\title{
EVALUATION OF NURSE PRESCRIBING IN PALLIATIVE CARE IN UGANDA: SHAPING THE FUTURE FOR GLOBAL PALLIATIVE CARE
}

\author{
J Downing J.1,2, W Acunda. ${ }^{3}$, D Adong ${ }^{3}$, E Luyirika ${ }^{4}$, E Namisango ${ }^{4}$, F Kiyange ${ }^{4}$, R Kiwanuka ${ }^{5}$, Amandua ${ }^{5}$ L Grant ${ }^{2}$, M Leng ${ }^{1,23}$ \\ and the Evaluation Team \\ 1. Makerere and Mulago Palliative Care Unit, 2. University of Edinburgh, 3. Hospice Africa Uganda, 4. African Palliative Care Association, \\ 5. Palliative Care Association of Uganda, 6. Ministry of Health, 7. Cairdeas International Palliative Care Trust
}

\section{BACKGROUND}

The WHA Resolution calls for the integration of palliative care (PC) into the health system, thus ensuring access to pain and symptom management for all. Uganda has led the way for palliative care developments within the region. A range of training programmes delivered to different health professionals, in particular nurses, have improved skills and increased the provision of PC to a high level. The models of PC delivery rely heavily on trained nurses. Thus nurses have a pivotal role in the provision of PC and often spearhead development, shaping and guiding PC provision. Uganda has led the way through PC trained nurses prescribing medications including oral morphine. However, no evaluation had been undertaken since its inception in 2004.

\section{AlM}

To determine the effectiveness of nurse prescribing in PC in Uganda.

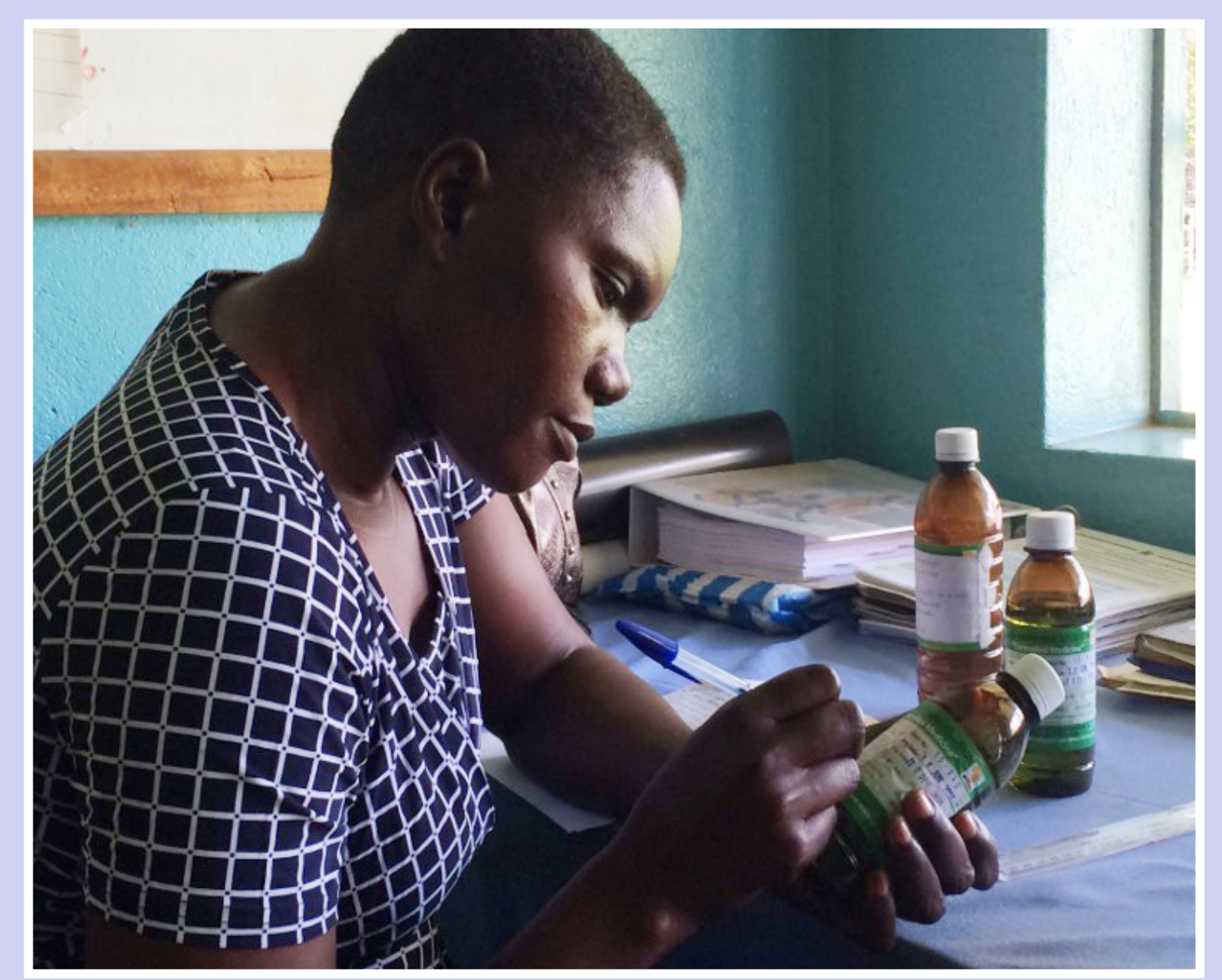

\section{METHODS}

A 3-phase mixed-methods evaluation examining:

\section{Training for nurse prescribing;}

- 13 nurses, 4 trainers and $1 \mathrm{MoH}$ colleague were interviewed;

- Core competencies for prescribing agreed through an expert workshop;

- A curriculum review undertaken.

\section{Analysis of nurse competency to assess \& manage pain, and appropriately prescribe;}

- 22 nurses managed 20 patients each, assessing and managing their pain and other symptoms, using the APCA POS on 3 sequential visits.

\section{Appraisal of the health-care system in 10 districts to understand the context within which nurses are working. \\ - Utilisation of rapid systems appraisal methodology in 10 districts in Uganda \\ - Interviews held with key stakeholders}

Ethical approval was gained from HAUREC/UNCST.

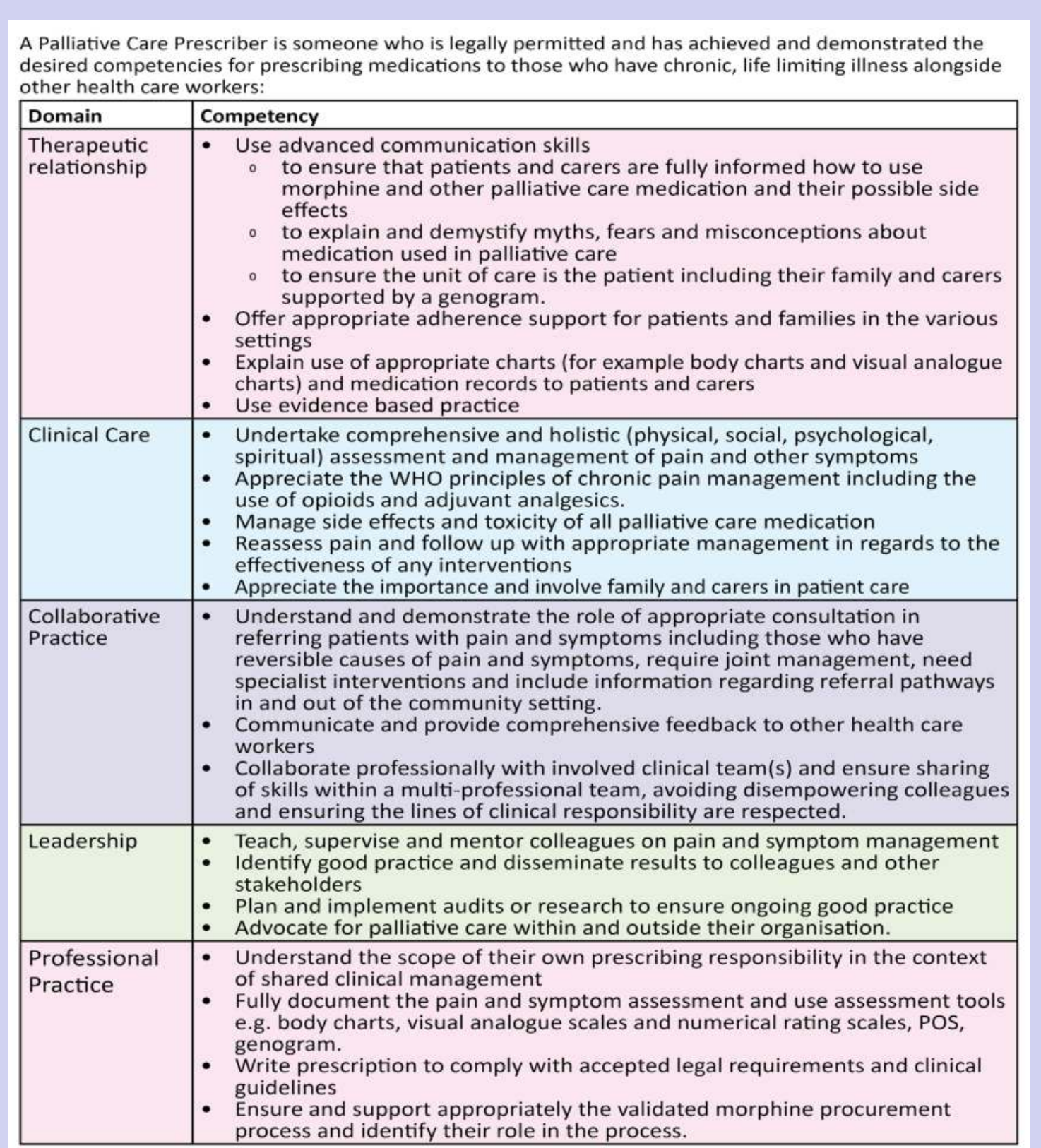

RESULTS

Results show nurses can assess and manage pain, including prescribing oral morphine.

\section{Preparation for the role:}

Themes impacting nurse preparation included:

- training,

- supervision and mentorship,

- competency,

- boundaries,

- beliefs and system issues.

Agreement was made with regards to core competencies for PC prescribing. The current curriculum, with minor adaptions, is 'fit-for-purpose'.

\section{Nurse Competency}

Nurses can assess and manage pain $(p<0.001)$ utilising appropriate medications and requesting support as patients required.

\section{The system in which the} nurses are working Nurses work in a system where:

- access to medications varies;

- there is limited understanding of PC and myths persist about the use of

\section{POS Q1: Please rate your pain during the last 3 days} morphine.

- However they are resilient and able to overcome challenges.

\section{CONCLUSIONS AND LESSONS LEARNT}

Training PC nurses to prescribe medications in order to increase access to PC is an important transferable model. Whilst challenges exist and recommendations are made to improve the system, this evaluation demonstrates the benefit and safety of nurse prescribing for PC in Uganda. This has important implications for shaping the future of global PC. 